\title{
Effects of back extensor strengthening exercises on postural alignment, physical function and performance, self-efficacy, and quality of life in Japanese community-dwelling older adults: A controlled clinical trial
}

\author{
Atsumi FuKUdA, PT, MSc. ${ }^{1}$, Eiki Tsushima, PT, PhD. ${ }^{2}$, \\ Kanichiro WADA, MD., PhD. ${ }^{3}$ and Yasuyuki IsHIBASHI, MD., PhD. ${ }^{3}$ \\ ${ }^{1)}$ Doctoral Program, Graduate School of Health Science, Hirosaki University \\ ${ }^{2)}$ Graduate School of Health Science, Hirosaki University \\ ${ }^{3}$ Department of Orthopedic Surgery, Hirosaki University Graduate School of Medicine
}

\begin{abstract}
Objective: To examine the changes in postural alignment and kyphosis-correlated factors after 6 months of back extensor strengthening exercise in a group of community-dwelling older adults aged $\geq 65$ years. Methods: We quasi-randomized 29 subjects into an intervention group treated with a back extensor strengthening program and a control group treated with a full-body exercise program. These groups completed 20-30 minutes of exercise directed by a physical therapist one or more times per week and were instructed to exercise at home as well. The participants were assessed prior to and after the intervention using the following criteria: postural alignment of "usual" and "best" posture, physical function, physical performance, self-efficacy, and quality of life. The differences between two factors (group and period) were compared for each of the measurement variables. Results: Subjects who adequately completed the exercises were analyzed. A reduced knee flexion angle was noted in the "best" posture of both groups, as were improved physical function and performance with the exception of one-leg standing time. Verifying the effect size in the post-hoc analysis, the body parts that showed changes to postural alignment after the intervention differed between groups. Conclusions: Back extensor strengthening exercises improved physical function and performance, but did not improve spinal alignment. The changes due to these interventions were not significantly different from changes observed in the full-body exercise group. However, post-hoc analysis revealed that the effect size of posture change was different, possible indicating that the two groups experienced different changes in the postural alignment.
\end{abstract}

Key words: back extensor strengthening exercise, community-dwelling older adults, postural alignment

(Phys Ther Res 23: 132-142, 2020)

\footnotetext{
A ge-related hyperkyphosis is assumed to be associated with vertebral fractures caused by osteoporosis. However, in prior studies when the kyphosis angles of the thoracic vertebrae of older adults were measured and classified into

Received: October 21, 2019

Accepted: April 2, 2020

Advance Publication by J-STAGE: August 5, 2020

Correspondence to: Atsumi Fukuda, Doctoral Program, Graduate School of Health Science, Hirosaki University, 66-1 Hon-cho, Hirosaki, Aomori 036-8564, Japan

\# e-mail: atsumi.note@gmail.com

doi: 10.1298/ptr.E10013
}

three levels, only about one-third of patients with the greatest angle had vertebral fractures ${ }^{1,2)}$. Kyphosis deformity is thought to be a geriatric syndrome seen in an estimated 20$40 \%$ of older adults ${ }^{3}$. Not only does it entail such changes in outward appearance, it is associated with adverse health outcomes such as poor physical function ${ }^{4-6)}$, falls ${ }^{7)}$, decreased quality of life ${ }^{8)}$, and increased mortality risks ${ }^{11}$.

A past review article summarized the various interventions aimed at improving kyphosis posture ${ }^{9)}$. One such intervention focused on exercise-based interventions. Few researchers have used only back extensor strengthening in the prone position. Most recent reports use the back extensor 


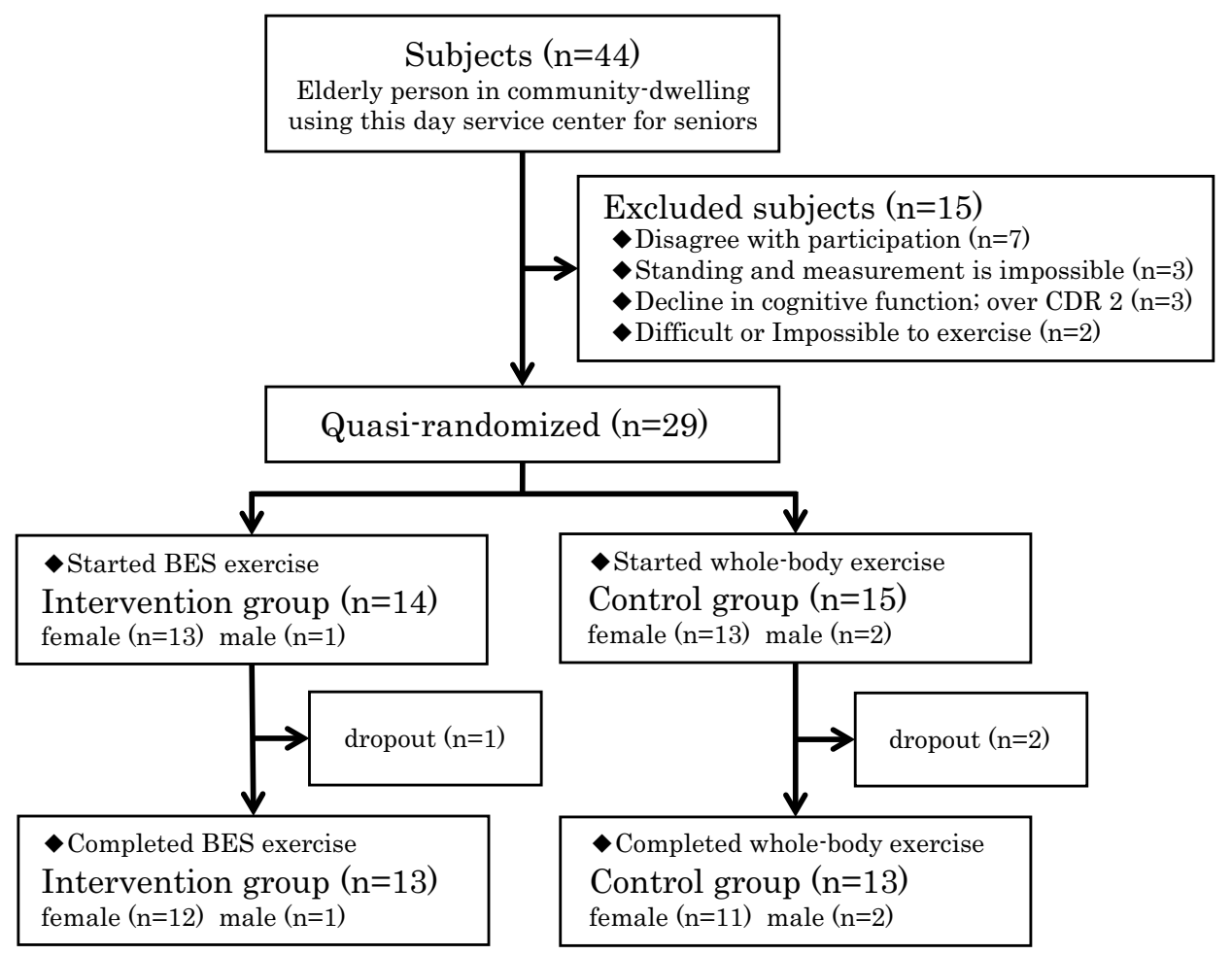

Figure 1. Flow chart.

strengthening in the sitting position ${ }^{10,11)}$, standing position, and all-fours position. Multidimensional exercise intervention, particularly involving back muscle reinforcement has been shown to improve posture ${ }^{12)}$.

In many previous studies ${ }^{13-16)}$, the exercise time was set at the long period of 60 minutes and full-body type exercises involving the trunk and upper and lower extremities were performed which may have contributed to the posture improvements observed. However, we believe that, for programs for posture improvement oriented toward older adults, simple and quick methods may be most appropriate. Moreover, while back extensor strengthening has been important to date, its efficacy independent of other exercises has not been adequately examined; as such, there is room for review with regard to methods and implementation time.

The purpose of this study was to evaluate 6 months of exercises focusing on back extensor strengthening, improvement of postural alignment, kyphosis-related factors on physical function, physical performance, and healthrelated quality of life (HQOL) in community-dwelling older adults $\geq 65$ years old.

\section{Methods}

\section{Participants}

The study subjects were older adults who frequented one of the seniors' day service center (day service center) in Hirakawa city, Aomori prefecture Japan, from April to June 2018.
Based on information from the long-term care manager (care manager), the study supervisor directly and verbally invited 44 people who had not sustained bone fracture or surgeries in the preceding 6 months and were able to stand and walk. Of them, 29 who did not have a decline in cognitive function (Clinical Dementia Rating ${ }^{17)}$ of $\leq 1$ ) agreed to perform exercises once or more per week under the guidance of a physical therapist (PT).

We explained the study's aims and procedures to the subjects; all subjects provided written consent. This study was approved by The Committee of Medical Ethics of Hirosaki University Graduate School of Health Sciences, Hirosaki, Japan (reference no. 2017-048).

\section{Intervention}

At intervention initiation, the study supervisor asked the subjects to draw an envelope containing a paper on which the group assignment was written. Subsequently, 29 subjects were randomized (14 to the intervention group and 15 to the control group) (quasi-randomization) (Figure 1). Participants in the intervention group completed a back extensor strengthening program that included the following: at a sitting position: 1) shoulder elevation, 2) shoulder horizontal abduction, and 3) shoulder extension; at a standing position: 4) push up and 5) one arm and the opposite leg lift. These programs were selected from programs commonly used in previous studies ${ }^{13-16)}$ (Figure 2). Participants in the control group completed a full-body exercise that included the following: at a sitting position: 1) hip flexion, 2) knee extension, and 3 ) hip abduction; and at a standing po- 


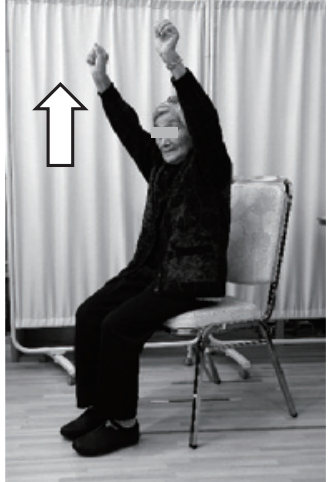

A

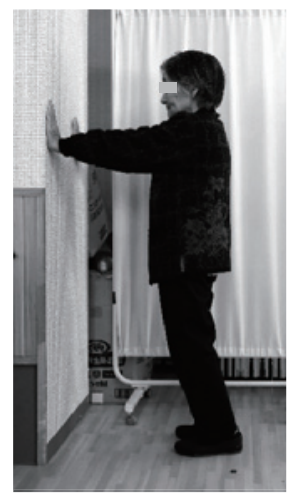

D
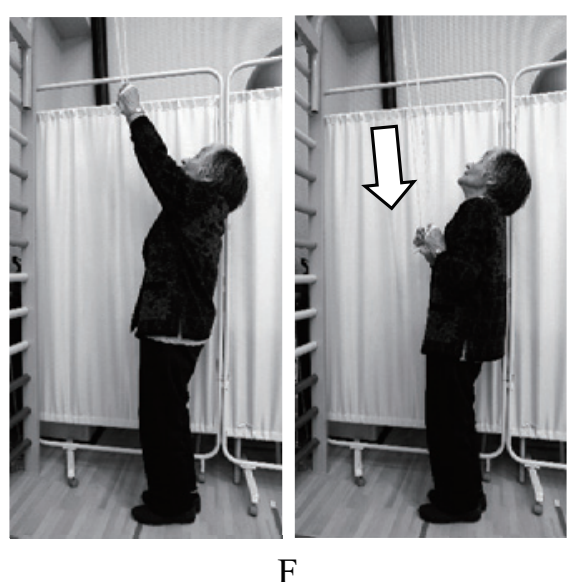

F

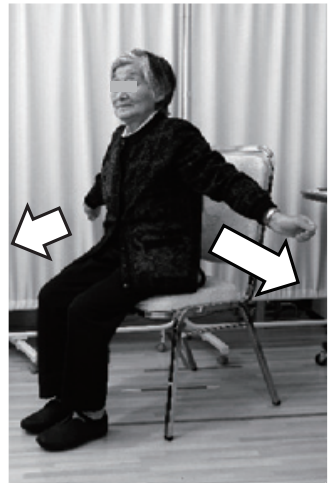

B

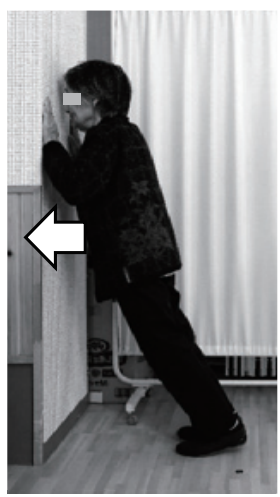

D

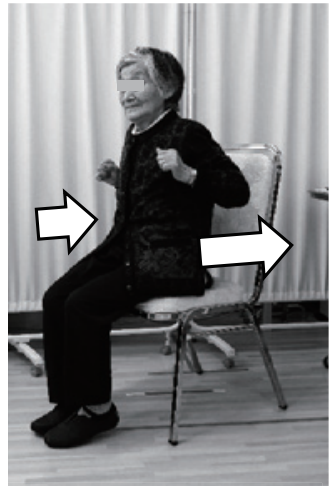

C

Figure 2. Back extensor strengthening exercise in intervention group.

Start program A to E, A: shoulder elevation, B: shoulder horizontal abduction, C: shoulder extension, D: push up at wall or bar, E: one arm and the opposite leg lift. A to C: sitting position, D and E: standing position (with on hands). F: pull down in standing position in an additional program. G: one arm and the opposite leg lift on all fours changed after possible E position.

sition: 4) squat and 5) calf raise. Each group was given five exercises. These exercises were configured based on programs often used in clinical practice (Figure 3).

One or more times per week, the subjects conducted these exercises under the guidance of a PT, who was also the study supervisor. The implementation time was 20-30 minutes with an exercise intensity of 10 repetitions per set and starting with no load. The PT adjusted the exercise intensity such that it would not exceed 12-13 on the Borg scale for a rating of perceived exertion (RPE), while verify- ing that the subjects were performing the exercises adequately without pain or discomfort. Specifically, using RPE as an indicator, exercise intensity was adjusted by increasing the number of sets up to 2 sets of 10 repetitions using weights or the elastic bands (Thera-band ${ }^{\circledR}$ ) when it became possible to add them to the program. The weights were 1.0$2.0 \mathrm{~kg}$, and Thera-band ${ }^{\circledR}$ were yellow, red, or green. Subjects were instructed to exercise at home every day if possible, with the frequency of implementation being verified by an exercise $\log$. 


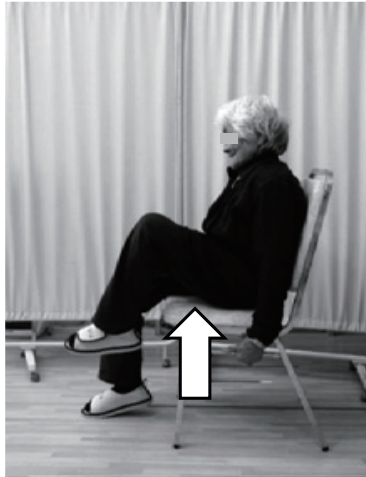

$\mathrm{H}$

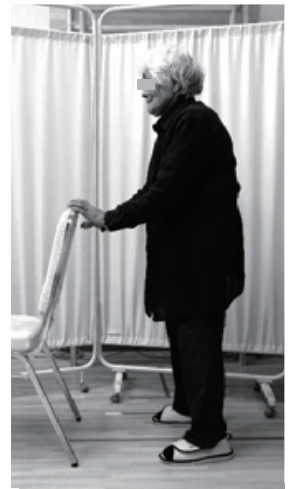

K

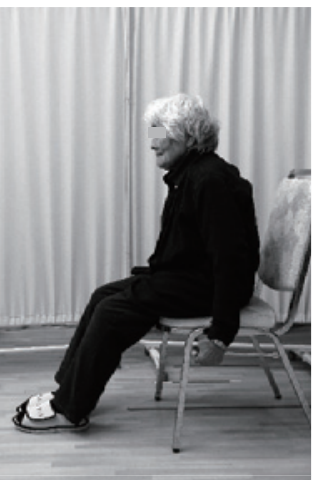

M

K

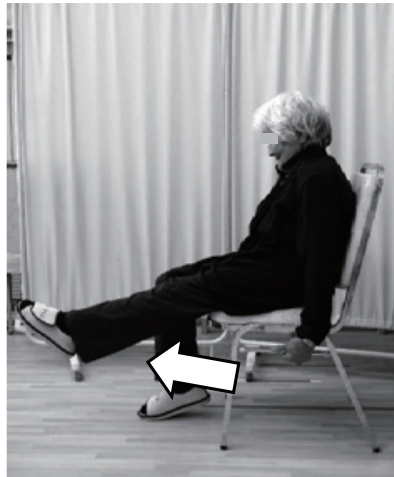

I
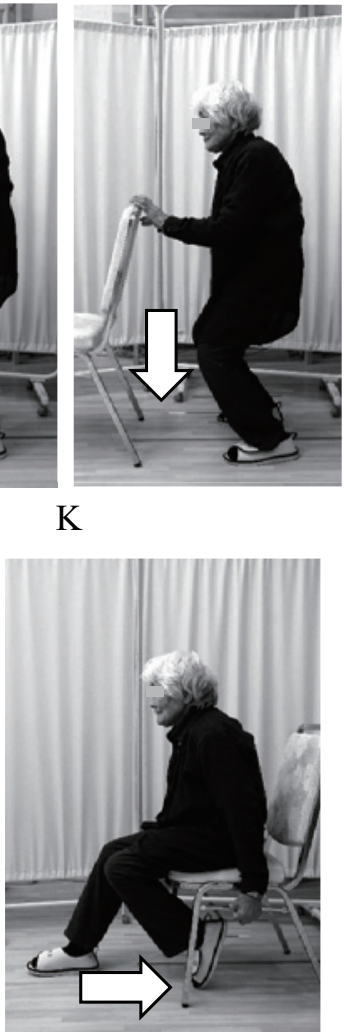

Figure 3. Whole-body exercise in control group.

It shows start program $\mathrm{H}$ to L, H: hip flexion, I: knee extension, J: hip abduction, K: squat, L: calf raise. $\mathrm{H}$ to $\mathrm{J}$ : sitting position, $\mathrm{K}$ and $\mathrm{L}$ : standing position with support of the hands. M: knee flexion in sitting position in an additional program. $\mathrm{N}$ : squat without support changed after $\mathrm{K}$ was enabled.

\section{Measures}

At the time before the intervention and at 3 and 6 months after the intervention, we assessed the following: postural alignment, physical function, physical performance, self-efficacy, and HQOL. All measurements and records were managed by the study supervisor.

The intra-rater reliability of each measurement variable (spinal curvature angle, physical function, and physical performance) was measured using the Shrout ${ }^{18)}$ intraclass correlation coefficient (ICC). The right one-leg standing time (OLS) ICC $(1,1)$ was $\rho=0.63$, substantially low $^{19}$ for the criterion, but the other items were $\rho=0.87-0.98$, having almost perfect high reliability ${ }^{19}$. To seek the measurement frequency to fulfill the target coefficient value of $\rho=0.81$, the OLS was calculated with Spearman-Brown's formula and decided to use the average of three measurements. For the other items, we used the averages of two measurements.

\section{Baseline data}

From the interviews, primary doctor and care manager information records, we confirmed the subjects' age, nursing care level, occupational history, and medical information. We also calculated their body mass index (BMI). The start time data of each group showed no significant differ- 
Table 1. Baseline data.

\begin{tabular}{|c|c|c|c|}
\hline & $\begin{array}{l}\text { Intervention group } \\
\qquad(\mathrm{n}=14)\end{array}$ & $\begin{array}{l}\text { Control group } \\
(\mathrm{n}=15)\end{array}$ & $\begin{array}{c}\text { Comparison, } \\
\text { p value }\end{array}$ \\
\hline Age (year) & $82.9 \pm 4.6$ & $83.9 \pm 6.2$ & $\mathrm{a} 0.65$ \\
\hline Height $(\mathrm{cm})$ & $145.4 \pm 6.9$ & $144.8 \pm 7.6$ & $\mathrm{a} 0.82$ \\
\hline $\mathrm{BMI}\left(\mathrm{kg} / \mathrm{m}^{2}\right)$ & $25.4 \pm 2.6$ & $24.0 \pm 4.4$ & $\mathrm{a} 0.31$ \\
\hline \multicolumn{4}{|l|}{ Gender* } \\
\hline male, female & 1,13 & 2,13 & $\mathrm{~b} 0.53$ \\
\hline \multicolumn{4}{|l|}{ Past or surgery history* } \\
\hline Cerebrovascular disorder & 3 & 3 & $\mathrm{~b} 0.64$ \\
\hline \multicolumn{4}{|l|}{ Orthopedic disorder } \\
\hline Vertebral compression & 1 & 2 & $\mathrm{~b} 0.53$ \\
\hline Lumbar spondylosis & 2 & 4 & $\mathrm{~b} 0.36$ \\
\hline Femoral neck fracture & 1 & 4 & $\mathrm{~b} 0.19$ \\
\hline Knee osteoarthritis & 7 & 7 & $\mathrm{~b} 0.58$ \\
\hline Total knee arthroplasty & 2 & 2 & $\mathrm{~b} 0.68$ \\
\hline \multicolumn{4}{|l|}{ Nursing care level* } \\
\hline Support level 1, 2 & 1,6 & 1,4 & \\
\hline Care level 1, 2 & 2,1 & 8,1 & $\mathrm{~b} 0.16$ \\
\hline Comprehensive service & 4 & 1 & \\
\hline \multicolumn{4}{|l|}{ Cognitive function* } \\
\hline $\operatorname{CDR} 0,0.5,1$ & $11,2,1$ & $11,3,1$ & b 1.00 \\
\hline \multicolumn{4}{|l|}{ Occupational history $\dagger$} \\
\hline Agriculture & $9(64.3)$ & $12(80.0)$ & $\mathrm{b} 0.30$ \\
\hline
\end{tabular}

Values represent the mean \pm standard deviation (SD), BMI: body mass index, CDR: clinical dementia rating. *: number, $\dagger$ : number (\%), a two samples t-test (after ShapiroWilk test and Levene test), b chi-square test.

ences on a two-samples t-test or a chi-square test (Table 1).

Primary outcome measures

\section{Postural alignment}

We used the following as indicators for each section while in the standing position posture within the sagittal plane: spinal curvature angle, forward head posture (head posture), and knee joint angle (knee angle). Using Katzman's methods of measurement ${ }^{16)}$, each measurement was performed at "usual" and "best" posture. For "usual" posture, subjects were instructed to "stand as relaxed as they usually do." While for "best" posture, subjects were instructed to "stand upright and stand up as tall as possible."

We used a spinal column shape measurement analyzer (Idiag, SpinalMouse ${ }^{\circledR}$ ) for the spinal curvature angle and calculated the thoracic kyphosis angle, the lumbar lordosis angle, the sacral inclination angle, and the spinal inclination angle. The analyzer used a three-axis acceleration sensor and could be measured easily in a short time. The intra- and inter-rater reliabilities were 0.8 or higher ${ }^{20)}$, and criterionrelated validity of the analyzer has been confirmed ${ }^{21)}$.

For head posture and knee angle, photographs were taken using a digital still camera (SONY, $\alpha 6000$ ), and these items were calculated based on these photographs using image analysis software Image J ver. 1.51 (freeware). Head posture was considered as the distance between the back of the heel and the vertical line running through the earlobe.

Secondary outcome measures

Physical function

1. Back extensor strength

Back extensor strength (BES) was measured using the manual muscle strength testing device (SAKAI Medical Co., Mobie MT-100) invented by Endo et al. ${ }^{22)}$, set between the 7 thoracic vertebrae and the wall using the pressurizing method. The subjects were instructed to cross both arms in front of their chests, in a sitting posture, and conduct a 3 second isometric contraction.

\section{Trunk flexion and extension range of motion}

Using SpinalMouse ${ }^{\circledR}$, we measured the spinal curvature angle in the trunk's maximum flexion position and maximum extension position. We calculated the flexion range of motion (ROM) and the extension ROM for each section of the spinal column.

\section{Physical performance}

\section{Five-repetition sit-to-stand test}

Following the Csuka et al. ${ }^{23)}$ method, we measured the time taken to complete five repetitions of a standing and sitting movement from a $40-\mathrm{cm}$ table as quickly as possible.

2. One-leg standing time 
We measured the length of time for which the subjects could hold a one-leg foot standing position with the eyes open and both hands on the hips.

\section{Five-meter maximum gait speed}

Subjects were instructed to walk as quickly as possible along a walking path and measured the elapsed time at the point at which they completed a measured distance of $5 \mathrm{~m}$.

\section{Japanese-version physical performance test}

We used a Japanese version of the physical performance test (JPPT) ${ }^{24,25)}$. This test has score totals of 0-28 points and consists of seven items. Devised from the functional perspectives of upper body strength and dexterity, mobility, and stamina, higher scores indicate better physical performance.

Self-efficacy

We translated the falls efficacy scale $(\mathrm{FES})^{26)}$, oriented it toward older Japanese adults and used a questionnaire modified to have responses from one of four options of levels. The questionnaire consisted of 10 items with scores of 10-40. Higher scores indicate higher confidence in the accomplishment of daily activities.

$H Q O L$

We used the questionnaire SF- ${ }^{\mathrm{TM}}$ Health Survey (24 h, Japanese version $)^{27)}$. Two summary scores, PCS and MCS, were calculated based on eight subscales.

\section{Statistical analysis}

Comparison of all subjects

We conducted an analysis of variance using a mixed effects model for repeated measures to determine whether there was a difference between the two factors (group, period) for each measurement variable ("usual" and "best" posture postural alignment, physical function, physical performance, self-efficacy, and HQOL) in the intervention and control groups caused by the exercise intervention. When the main effect was significant, we used a multiple comparison procedure with Bonferroni correction and compared the difference between the levels.

Comparison of test subjects who completed the exercise intervention

We excluded subjects who did not complete their exercise implementation at a frequency of $\geq 90 \%$ twice per week or more including PT instruction once per week or more and included only those who completed the exercise intervention according to the plan and for whom no measurement data were missing. We compared the two factors in each measurement variable using analysis of variance for split-plot factorial design and when the main effect was significant, a multiple comparison procedure with the Bonferroni method was applied.

As a post-hoc analysis, regarding the postural alignment variables, we used a two-samples t-test to analyze the differences in (1) measured values before and 6 months after the intervention for each group; and (2) the intergroup changes after the intervention. The effect size $r$ was calculated to examine whether the difference pre- to postintervention meant a substantial difference, and how much power (1- $\beta$ ) was also confirmed.

For the above analysis, we used R 2.8.1 (freeware), SPSS ver. 24.0 (IBM), and G*Power 3.1.9.4 (freeware) and statistical significance was set at $\mathrm{p}<0.05$.

\section{Results}

One subject from the intervention group dropped out of the study because of not wanting to continue exercising but measurements were possible for all items in each period. Two subjects in the control group also dropped out, one of whom withdrew consent to participate due to discontinuing their use of the day service center, while the other stopped midway due to the occurrence of increased pain in both knees, a symptom that the subject had had in the past and was unrelated to the exercises in this study. Subjects who completed the assessments at all measurement periods included 14 in the intervention group and 13 in the control group.

Eight people received PT instruction once per week, 15 twice per week, and three received more than three sessions of PT per week. With regard to home exercise frequency, eight people did not participate in home practice, two people had home practice 2-3 times a week, 11 people participated four times or more a week. Five people performed TV exercises and walks that were different from the intervention program. The total frequency was two subjects fewer than one per week, six people about once a week, five people about 2-3 times a week, and 13 people had more than four times per week.

\section{Comparison of all subjects}

There were no significant intergroup differences in any of the measurement variables. The variables that showed main effects in the period factor were the "best" posture's head posture, lumbar extension ROM, BES, 5repetition sit-to-stand test (SS-5), OLS, gait speed, and JPPT, but there were no significant differences in the "usual" posture's postural alignment or in FES and SF-8. A group $\times$ period interaction was seen in the thoracic kyphosis angle in the "usual" posture $(\mathrm{F}=3.29, \mathrm{p}=0.045)$ and "best" posture $(\mathrm{F}=5.92, \mathrm{p}=0.005)$, but because there were no significant differences in the other items, there were no intergroup differences in the intervention results.

The differences at each level showed a negative change in postural alignment, such that the "best" posture's head posture was significantly farther forward $(\mathrm{p}<0.05)$ at 3 months after the intervention. Significant improvement was seen at 3 months after the start of intervention for lumbar extension ROM, BES, SS-5, gait speed, and JPPT (all p< $0.01)$. OLS was significantly prolonged at 6 months after 
Table 2. Comparison of all measured subjects.

\begin{tabular}{|c|c|c|c|c|c|c|c|c|}
\hline & \multicolumn{3}{|c|}{ intervention group } & \multicolumn{3}{|c|}{ control group } & \multicolumn{2}{|c|}{$\mathrm{p}$ value } \\
\hline & $\begin{array}{l}\text { baseline } \\
(n=14)\end{array}$ & $\begin{array}{c}3 \text { months } \\
(\mathrm{n}=14)\end{array}$ & $\begin{array}{c}6 \text { months } \\
(\mathrm{n}=14)\end{array}$ & $\begin{array}{c}\text { baseline } \\
(\mathrm{n}=15)\end{array}$ & $\begin{array}{l}3 \text { months } \\
(\mathrm{n}=14)\end{array}$ & $\begin{array}{c}6 \text { months } \\
(\mathrm{n}=13)\end{array}$ & group & period \\
\hline Height $(\mathrm{cm})$ & $145.4 \pm 6.9$ & $145.8 \pm 6.2$ & $145.4 \pm 6.6$ & $144.8 \pm 7.6$ & $144.9 \pm 8.0$ & $145.5 \pm 7.6$ & 0.79 & 0.80 \\
\hline \multicolumn{9}{|l|}{ postural alignment } \\
\hline \multicolumn{9}{|l|}{ "usual" posture } \\
\hline Thoracic kyphosis (deg) & $35.8 \pm 17.2$ & $38.4 \pm 17.7$ & $40.6 \pm 15.9$ & $44.8 \pm 13.6$ & $41.0 \pm 14.9$ & $42.9 \pm 15.3$ & 0.40 & 0.37 \\
\hline Lumber lordosis (deg) & $5.0 \pm 18.8$ & $2.4 \pm 21.5$ & $4.1 \pm 22.3$ & $-1.6 \pm 21.1$ & $0.4 \pm 24.0$ & $-1.2 \pm 24.6$ & 0.56 & 0.97 \\
\hline Sacral inclination (deg) & $5.3 \pm 10.8$ & $4.8 \pm 10.2$ & $5.0 \pm 9.7$ & $9.1 \pm 10.3$ & $9.2 \pm 9.7$ & $7.5 \pm 6.8$ & 0.30 & 0.80 \\
\hline Spinal inclination (deg) & $18.7 \pm 11.3$ & $17.5 \pm 10.2$ & $18.7 \pm 10.6$ & $18.5 \pm 16.1$ & $19.3 \pm 15.4$ & $16.7 \pm 14.4$ & 0.99 & 0.84 \\
\hline Head posture $(\mathrm{cm})$ & $13.8 \pm 6.0$ & $13.5 \pm 4.8$ & $13.9 \pm 5.1$ & $14.2 \pm 5.0$ & $13.3 \pm 5.8$ & $13.7 \pm 5.6$ & 0.93 & 0.43 \\
\hline Knee angle (deg) & $14.3 \pm 8.8$ & $13.8 \pm 6.9$ & $14.2 \pm 7.9$ & $14.7 \pm 5.4$ & $16.3 \pm 6.5$ & $14.0 \pm 4.1$ & 0.71 & 0.39 \\
\hline \multicolumn{9}{|l|}{ "best" posture } \\
\hline Thoracic kyphosis (deg) & $31.8 \pm 16.7$ & $35.6 \pm 17.9$ & $36.3 \pm 15.4$ & $39.7 \pm 12.9$ & $35.2 \pm 15.8$ & $38.1 \pm 15.7$ & 0.59 & 0.37 \\
\hline Lumber lordosis (deg) & $2.9 \pm 19.1$ & $2.1 \pm 21.1$ & $2.0 \pm 21.3$ & $-3.0 \pm 21.6$ & $-1.4 \pm 21.3$ & $-3.5 \pm 24.2$ & 0.53 & 0.79 \\
\hline Sacral inclination (deg) & $4.8 \pm 10.3$ & $3.8 \pm 10.7$ & $4.3 \pm 10.1$ & $7.0 \pm 11.9$ & $8.5 \pm 7.1$ & $8.0 \pm 8.8$ & 0.31 & 0.96 \\
\hline Spinal inclination (deg) & $15.7 \pm 10.0$ & $15.6 \pm 8.7$ & $14.9 \pm 10.0$ & $13.6 \pm 13.9$ & $14.9 \pm 11.5$ & $14.1 \pm 11.1$ & 0.79 & 0.84 \\
\hline Head posture $(\mathrm{cm})$ & $10.4 \pm 5.2$ & $10.4 \pm 5.1$ & $11.6 \pm 5.1 * * \dagger$ & $10.6 \pm 4.1$ & $11.2 \pm 5.6$ & $12.8 \pm 5.5^{* * \dagger}$ & 0.70 & $<0.01$ \\
\hline Knee angle (deg) & $13.8 \pm 9.6$ & $12.2 \pm 7.2$ & $12.6 \pm 8.9$ & $13.9 \pm 5.5$ & $13.0 \pm 6.8$ & $10.9 \pm 5.2$ & 0.93 & 0.09 \\
\hline \multicolumn{9}{|l|}{ physical function } \\
\hline BES (kg) & $10.5 \pm 3.6$ & $14.8 \pm 4.1 * *$ & $14.9 \pm 4.9 * *$ & $9.2 \pm 2.2$ & $12.3 \pm 3.4 * *$ & $12.9 \pm 3.3 * *$ & 0.10 & $<0.01$ \\
\hline \multicolumn{9}{|l|}{ Trunk ROM } \\
\hline Thoracic flex. ROM (deg) & $10.7 \pm 11.0$ & $14.9 \pm 13.3$ & $11.0 \pm 7.0$ & $3.7 \pm 6.2$ & $7.1 \pm 8.0$ & $7.8 \pm 11.5$ & 0.06 & 0.12 \\
\hline Lumber flex. ROM (deg) & $19.8 \pm 10.1$ & $18.9 \pm 9.5$ & $17.8 \pm 10.4$ & $13.0 \pm 9.4$ & $17.3 \pm 8.7$ & $17.4 \pm 5.7$ & 0.24 & 0.71 \\
\hline Thoracic ext. ROM (deg) & $-3.8 \pm 7.8$ & $-3.9 \pm 8.8$ & $-3.1 \pm 5.4$ & $-5.6 \pm 6.5$ & $-5.5 \pm 6.6$ & $-1.3 \pm 6.5$ & 0.78 & 0.27 \\
\hline Lumber ext. ROM (deg) & $-3.2 \pm 8.1$ & $0.6 \pm 10.4$ & $-5.5 \pm 6.3 \dagger$ & $-1.7 \pm 8.1$ & $0.2 \pm 7.6$ & $-5.4 \pm 7.4 \dagger$ & 0.92 & $<0.05$ \\
\hline Sacral ext. ROM (deg) & $-9.2 \pm 6.2$ & $-9.9 \pm 10.5$ & $-8.6 \pm 4.3$ & $-9.0 \pm 8.4$ & $-11.3 \pm 9.9$ & $-7.7 \pm 5.5$ & 0.99 & 0.20 \\
\hline Spinal ext. ROM (deg) & $-12.1 \pm 8.2$ & $-10.8 \pm 11.2$ & $-14.1 \pm 8.2$ & $-12.5 \pm 8.4$ & $-13.6 \pm 8.5$ & $-13.2 \pm 8.4$ & 0.75 & 0.55 \\
\hline \multicolumn{9}{|l|}{ physical performance } \\
\hline SS-5 (sec) & $17.4 \pm 6.6$ & $13.1 \pm 3.6^{* *}$ & $12.7 \pm 3.1 * *$ & $17.2 \pm 6.7$ & $12.7 \pm 3.9 * *$ & $11.8 \pm 3.0^{* *}$ & 0.84 & $<0.01$ \\
\hline OLS (sec) & $7.1 \pm 9.2$ & $10.5 \pm 13.0$ & $11.9 \pm 16.1^{*}$ & $4.3 \pm 5.8$ & $3.7 \pm 4.6$ & $4.9 \pm 5.3 *$ & 0.13 & $<0.05$ \\
\hline Gait speed (m/sec) & $0.9 \pm 0.4$ & $1.0 \pm 0.3 * *$ & $1.1 \pm 0.4 * *$ & $0.9 \pm 0.3$ & $1.0 \pm 0.3 * *$ & $1.0 \pm 0.3 * *$ & 0.66 & $<0.01$ \\
\hline JPPT (/28point) & $17.3 \pm 3.8$ & $19.0 \pm 4.2 * *$ & $19.0 \pm 3.8 * *$ & $16.3 \pm 3.3$ & $18.6 \pm 3.1 * *$ & $18.5 \pm 3.1 * *$ & 0.52 & $<0.01$ \\
\hline \multicolumn{9}{|l|}{ Self-efficacy } \\
\hline FES (/40point) & $27.8 \pm 4.4$ & $28.9 \pm 4.6$ & $28.2 \pm 3.1$ & $27.7 \pm 3.6$ & $27.6 \pm 3.1$ & $28.0 \pm 2.6$ & 0.76 & 0.60 \\
\hline \multicolumn{9}{|l|}{ HQOL } \\
\hline \multicolumn{9}{|l|}{ SF-8: } \\
\hline PCS & $41.5 \pm 9.8$ & $43.2 \pm 6.1$ & $42.3 \pm 7.7$ & $39.3 \pm 6.6$ & $41.0 \pm 5.8$ & $42.9 \pm 5.6$ & 0.51 & 0.29 \\
\hline MCS & $47.9 \pm 7.5$ & $48.5 \pm 8.1$ & $46.5 \pm 6.4$ & $46.9 \pm 5.2$ & $47.5 \pm 4.3$ & $46.1 \pm 6.6$ & 0.94 & 0.35 \\
\hline
\end{tabular}

Values are shown as mean $\pm \mathrm{SD}$, or $\mathrm{p}$ value in multiple comparison procedure with Bonferroni correction. Comparison with baseline: $* \mathrm{p}<0.05, * * \mathrm{p}<0.01$; comparison with 3 months: $\dagger \mathrm{p}<0.05$.

BES: back extensor strength; ROM: range of motion; SS-5: 5-repetition sit-to-stand; OLS: one-leg standing time; Gait speed: 5-m maximum gait speed; JPPT: Japanese Physical Performance Test; FES: fall efficacy scale; SF-8: SF-8тм Health Survey; PCS: Physical component summary, MCS: Mental component summary.

the intervention $(\mathrm{p}<0.05)$ (Table 2$)$.

Comparison of test subjects who completed the exercise intervention

There were 16 subjects included in the analysis (seven in the intervention group, nine in the control group). The main effect in the group factor was seen in lumbar flexion ROM and SS-5. There was a main effect in the period fac- tor for "best" posture's head posture and knee angle, lumbar extension ROM, BES, SS-5, gait speed, and JPPT, but there were no significant differences in the "usual" posture's postural alignment, FES, or SF-8. No mutual interaction was seen in any of the measurement variables.

Among levels, no significant differences were found for the "best" posture's head posture, while knee angle was significantly reduced at 6 months after the intervention. 
Table 3. Comparison of subjects who completed the exercise intervention.

\begin{tabular}{|c|c|c|c|c|c|c|c|c|}
\hline & \multicolumn{3}{|c|}{ intervention group } & \multicolumn{3}{|c|}{ control group } & \multicolumn{2}{|c|}{$\mathrm{p}$ value } \\
\hline & $\begin{array}{l}\text { baseline } \\
(\mathrm{n}=7)\end{array}$ & 3 months & 6 months & $\begin{array}{c}\text { baseline } \\
(\mathrm{n}=9)\end{array}$ & 3 months & 6 months & group & period \\
\hline Height (cm) & $145.4 \pm 7.3$ & $146.2 \pm 6.0$ & $145.5 \pm 6.5$ & $147.5 \pm 8.3$ & $147.3 \pm 8.7$ & $147.5 \pm 8.0$ & 0.66 & 0.73 \\
\hline \multicolumn{9}{|l|}{ postural alignment } \\
\hline \multicolumn{9}{|l|}{ "usual" posture } \\
\hline Thoracic kyphosis (deg) & $43.1 \pm 17.3$ & $42.1 \pm 17.0$ & $47.7 \pm 15.5$ & $47.9 \pm 10.4$ & $44.9 \pm 12.2$ & $47.4 \pm 11.1$ & 0.71 & 0.19 \\
\hline Lumber lordosis (deg) & $-2.1 \pm 16.9$ & $-4.9 \pm 24.1$ & $-2.4 \pm 25.2$ & $-3.3 \pm 19.2$ & $-0.5 \pm 19.9$ & $-2.3 \pm 19.6$ & 0.92 & 0.99 \\
\hline Sacral inclination (deg) & $4.7 \pm 7.4$ & $4.8 \pm 10.1$ & $4.9 \pm 10.1$ & $5.6 \pm 9.1$ & $6.3 \pm 9.8$ & $5.9 \pm 6.9$ & 0.79 & 0.97 \\
\hline Spinal inclination (deg) & $15.0 \pm 6.0$ & $12.9 \pm 6.4$ & $15.6 \pm 7.8$ & $14.5 \pm 8.1$ & $16.7 \pm 8.6$ & $15.8 \pm 12.0$ & 0.77 & 0.79 \\
\hline Head posture $(\mathrm{cm})$ & $12.8 \pm 2.6$ & $12.6 \pm 4.7$ & $12.5 \pm 3.8$ & $15.0 \pm 3.9$ & $13.7 \pm 4.6$ & $14.0 \pm 3.8$ & 0.38 & 0.65 \\
\hline Knee angle (deg) & $16.9 \pm 8.8$ & $15.0 \pm 6.3$ & $14.8 \pm 7.1$ & $15.2 \pm 6.3$ & $15.5 \pm 6.8$ & $12.8 \pm 4.4$ & 0.74 & 0.11 \\
\hline \multicolumn{9}{|l|}{ "best" posture } \\
\hline Thoracic kyphosis (deg) & $38.9 \pm 16.2$ & $41.9 \pm 15.2$ & $44.1 \pm 15.0$ & $42.5 \pm 9.2$ & $39.1 \pm 13.0$ & $41.8 \pm 11.0$ & 0.94 & 0.37 \\
\hline Lumber lordosis (deg) & $-4.1 \pm 17.0$ & $-6.1 \pm 22.6$ & $-4.9 \pm 24.1$ & $-3.0 \pm 20.3$ & $-2.6 \pm 17.1$ & $-4.1 \pm 19.0$ & 0.86 & 0.93 \\
\hline Sacral inclination (deg) & $4.1 \pm 9.4$ & $3.9 \pm 12.5$ & $4.1 \pm 11.3$ & $3.3 \pm 12.2$ & $6.7 \pm 7.1$ & $7.3 \pm 9.4$ & 0.73 & 0.45 \\
\hline Spinal inclination (deg) & $11.5 \pm 3.5$ & $11.6 \pm 5.0$ & $11.6 \pm 6.7$ & $10.4 \pm 5.8$ & $13.1 \pm 7.2$ & $14.0 \pm 8.2$ & 0.75 & 0.34 \\
\hline Head posture $(\mathrm{cm})$ & $9.6 \pm 3.1$ & $10.0 \pm 3.1$ & $11.4 \pm 3.3$ & $10.7 \pm 4.3$ & $11.8 \pm 3.9$ & $13.4 \pm 3.9$ & 0.45 & 0.02 \\
\hline Knee angle (deg) & $15.6 \pm 9.7$ & $13.1 \pm 5.1$ & $12.5 \pm 8.2 *$ & $13.9 \pm 6.4$ & $10.7 \pm 6.3$ & $9.2 \pm 5.2 *$ & 0.33 & 0.02 \\
\hline \multicolumn{9}{|l|}{ physical function } \\
\hline BES (kg) & $10.9 \pm 4.0$ & $15.2 \pm 3.3^{*}$ & $14.9 \pm 4.0^{* *}$ & $9.1 \pm 2.5$ & $12.6 \pm 3.9 *$ & $13.1 \pm 3.0 * *$ & 0.16 & $<0.01$ \\
\hline \multicolumn{9}{|l|}{ Trunk ROM } \\
\hline Thoracic flex. ROM (deg) & $9.9 \pm 6.0$ & $17.2 \pm 14.2$ & $10.6 \pm 7.2$ & $3.3 \pm 7.9$ & $6.5 \pm 10.0$ & $5.6 \pm 13.4$ & 0.09 & 0.18 \\
\hline Lumber flex. ROM (deg) & $24.8 \pm 3.1$ & $23.6 \pm 8.7$ & $22.5 \pm 7.3$ & $16.3 \pm 10.3$ & $18.6 \pm 9.3$ & $18.2 \pm 4.8$ & $<0.05$ & 0.96 \\
\hline Thoracic ext. ROM (deg) & $-2.3 \pm 10.3$ & $-2.6 \pm 7.6$ & $-4.6 \pm 5.5$ & $-4.9 \pm 7.9$ & $-5.4 \pm 8.0$ & $-1.3 \pm 7.7$ & 0.79 & 0.92 \\
\hline Lumber ext. ROM (deg) & $-3.4 \pm 11.0$ & $-2.1 \pm 12.4$ & $-8.2 \pm 7.0^{*}$ & $0.1 \pm 8.6$ & $-0.1 \pm 5.9$ & $-6.5 \pm 8.8^{*}$ & 0.49 & 0.05 \\
\hline Sacral ext. ROM (deg) & $-9.1 \pm 6.1$ & $-8.3 \pm 12.5$ & $-7.8 \pm 4.1$ & $-10.1 \pm 9.9$ & $-12.0 \pm 9.7$ & $-9.0 \pm 5.5$ & 0.87 & 0.61 \\
\hline Spinal ext. ROM (deg) & $-12.4 \pm 8.1$ & $-10.1 \pm 12.5$ & $-15.8 \pm 9.6$ & $-12.1 \pm 8.3$ & $-13.8 \pm 7.4$ & $-15.4 \pm 8.8$ & 0.97 & 0.21 \\
\hline \multicolumn{9}{|l|}{ physical performance } \\
\hline SS-5 (sec) & $18.5 \pm 4.2$ & $14.3 \pm 3.0 * *$ & $13.4 \pm 3.1 * *$ & $14.5 \pm 5.0$ & $11.0 \pm 2.4 * *$ & $10.6 \pm 1.3 * *$ & $<0.05$ & $<0.01$ \\
\hline OLS (sec) & $4.7 \pm 3.7$ & $7.6 \pm 8.2$ & $8.2 \pm 7.2$ & $4.7 \pm 7.2$ & $4.3 \pm 5.5$ & $5.5 \pm 5.8$ & 0.53 & 0.10 \\
\hline Gait speed $(\mathrm{m} / \mathrm{sec})$ & $0.8 \pm 0.3$ & $0.9 \pm 0.3^{*}$ & $0.9 \pm 0.3 * *$ & $1.0 \pm 0.3$ & $1.1 \pm 0.3 *$ & $1.1 \pm 0.3 * *$ & 0.17 & $<0.01$ \\
\hline JPPT (/28point) & $15.3 \pm 4.1$ & $17.0 \pm 4.8^{* *}$ & $17.1 \pm 4.2 * *$ & $17.4 \pm 3.4$ & $19.8 \pm 2.3 * *$ & $18.6 \pm 3.3 * *$ & 0.26 & $<0.01$ \\
\hline \multicolumn{9}{|l|}{ Self-efficacy } \\
\hline FES (/40point) & $28.6 \pm 4.7$ & $28.4 \pm 4.4$ & $27.4 \pm 3.3$ & $28.4 \pm 2.9$ & $27.9 \pm 3.8$ & $28.1 \pm 3.1$ & 0.99 & 0.68 \\
\hline \multicolumn{9}{|l|}{ HQOL } \\
\hline \multicolumn{9}{|l|}{ SF-8: } \\
\hline PCS & $42.2 \pm 4.7$ & $42.1 \pm 5.9$ & $43.9 \pm 6.6$ & $41.1 \pm 5.8$ & $41.9 \pm 6.2$ & $44.8 \pm 3.9$ & 0.96 & 0.11 \\
\hline MCS & $47.4 \pm 6.7$ & $48.9 \pm 8.6$ & $47.5 \pm 2.2$ & $48.3 \pm 4.5$ & $48.3 \pm 4.7$ & $46.7 \pm 7.8$ & 0.94 & 0.73 \\
\hline
\end{tabular}

Values are shown as mean $\pm \mathrm{SD}$, or $\mathrm{p}$ value in multiple comparison procedure with Bonferroni correction. Comparison with baseline: $* \mathrm{p}<0.05, * * \mathrm{p}<0.01$.

BES: back extensor strength; ROM: range of motion; SS-5: 5-repetition sit-to-stand; OLS: one-leg standing time; Gait speed: 5-m maximum gait speed; JPPT: Japanese Physical Performance Test; FES: fall efficacy scale; SF-8: SF-8TM Health Survey; PCS: Physical component summary, MCS: Mental component summary.

Lumbar extension ROM was significantly expanded at 6 months after the intervention $(\mathrm{p}<0.05)$, and BES, SS-5, gait speed, and JPPT were significantly improved at 3 and 6 months after the intervention (Table 3 ).

For the each-group effect size, variables larger than 0.5 of the evaluation criteria ${ }^{28)}$ were the thoracic kyphosis angles in the "usual" and "best" postures in the intervention group, and the spinal inclination angle and head posture in the "best" posture in the control group. The between-group effect sizes were small to moderate (Table 4).

\section{Discussion}

At 6 months post back extensor strengthening exercises, there were changes to postural alignment measurement variables with the exception of spinal curvature angle. 
Table 4. Change in postural alignment variables after the exercise intervention.

\begin{tabular}{|c|c|c|c|c|c|c|c|c|}
\hline & \multicolumn{3}{|c|}{ Intervention group $(n=7)$} & \multicolumn{3}{|c|}{ Control group $(n=9)$} & \multicolumn{2}{|c|}{ Comparison } \\
\hline & $\begin{array}{l}\text { 6month- } \\
\text { baseline }\end{array}$ & a $r$ & $\mathrm{a} 1-\beta$ & $\begin{array}{l}\text { 6month- } \\
\text { baseline }\end{array}$ & a $r$ & a1- $\beta$ & $\mathrm{b} \mathrm{r}$ & $\mathrm{b} 1-\beta$ \\
\hline Height $(\mathrm{cm})$ & $0.1 \pm 3.6$ & 0.04 & 0.05 & $0.0 \pm 0.8$ & 0.01 & 0.05 & 0.03 & 0.05 \\
\hline \multicolumn{9}{|l|}{ "usual" posture } \\
\hline Thoracic kyphosis (deg) & $4.6 \pm 6.3$ & 0.62 & 0.39 & $-0.4 \pm 8.0$ & 0.06 & 0.05 & 0.25 & 0.24 \\
\hline Lumber lordosis (deg) & $-0.3 \pm 11.0$ & 0.03 & 0.05 & $0.9 \pm 5.3$ & 0.19 & 0.08 & 0.08 & 0.06 \\
\hline Sacral inclination (deg) & $0.1 \pm 6.4$ & 0.02 & 0.05 & $0.4 \pm 7.2$ & 0.06 & 0.05 & 0.02 & 0.05 \\
\hline Spinal inclination (deg) & $0.6 \pm 4.0$ & 0.15 & 0.06 & $1.3 \pm 7.2$ & 0.02 & 0.08 & 0.07 & 0.06 \\
\hline Head posture $(\mathrm{cm})$ & $-0.3 \pm 2.3$ & 0.11 & 0.06 & $-1.0 \pm 2.9$ & 0.32 & 0.13 & 0.13 & 0.08 \\
\hline Knee angle (deg) & $-2.1 \pm 3.5$ & 0.55 & 0.34 & $-2.5 \pm 4.9$ & 0.47 & 0.28 & 0.04 & 0.05 \\
\hline \multicolumn{9}{|l|}{ "best" posture } \\
\hline Thoracic kyphosis (deg) & $5.2 \pm 8.8$ & 0.54 & 0.23 & $-0.7 \pm 7.8$ & 0.09 & 0.06 & 0.35 & 0.27 \\
\hline Lumber lordosis (deg) & $-0.7 \pm 10.0$ & 0.08 & 0.05 & $-1.1 \pm 12.3$ & 0.09 & 0.06 & 0.15 & 0.05 \\
\hline Sacral inclination (deg) & $-0.1 \pm 4.9$ & 0.02 & 0.05 & $4.0 \pm 8.3$ & 0.46 & 0.25 & 0.29 & 0.19 \\
\hline Spinal inclination (deg) & $0.1 \pm 6.0$ & 0.03 & 0.05 & $3.6 \pm 5.1$ & 0.58 & 0.44 & 0.31 & 0.21 \\
\hline Head posture $(\mathrm{cm})$ & $1.8 \pm 3.6$ & 0.47 & 0.20 & $2.7 \pm 3.0$ & 0.69 & 0.64 & 0.14 & 0.08 \\
\hline Knee angle (deg) & $-3.1 \pm 3.1$ & 0.73 & 0.70 & $-4.6 \pm 6.3$ & 0.61 & 0.47 & 0.16 & 0.09 \\
\hline
\end{tabular}

Values are shown as mean \pm SD. $r$, effect size $r$; $1-\beta$, power $(1-\beta)$; ar and a1- $\beta$, post hoc analysis of paired $t-$ test in intervention/control group after exercise intervention; br and ${ }^{b} 1-\beta$, post hoc analysis two-sample $t$ test of the two groups.

However, while improvements were seen in the lumbar extension ROM, physical function, and physical performance, no significant intergroup differences were observed. There were also no major changes in the results for subjects who kept up a frequency of exercise implementation twice or more per week except that positive changes were seen in the knee angle in the "best" posture and the point that OLS as physical performance did not significantly change. This was different from the results of the analysis of all subjects.

There were no intergroup differences in improvement after the intervention, but in the post-hoc analysis, regarding posture, the intervention group's thoracic kyphosis in the "usual" and "best" posture increased significantly and the control group's "best" posture's trunk forward tilt and head forward change were large. These are all negative changes, but it is conceivable that, in the intervention group, trunk forward tilt and head forward change did not progress; in the control group, the thoracic kyphosis angle was maintained. Thus, it is possible that the effects of each exercise program are different.

Bergström et al. ${ }^{13)}$ conducted a back extensor strengthening program including squats and heel-rises. The results of a per-protocol analysis showed significant improvements in the BES and thoracic expansion of the training group but no significant changes in the kyphosis or C7-to-wall distance; they reported that the mean height of those in the non-intervention control group decreased significantly. It is not possible to compare our results with those because the hypothesized parent set was significantly different to the one in this study and the effect size was not indicated.
However, although BES improvement was observed in this study, neither study reported changes in kyphosis or head posture. Both groups in this study maintained their height without significant changes, so it is possible that this was an effect of the exercise.

Benedetti et al. ${ }^{15)}$ had the intervention group perform a back extensor strengthening program including pelvic and shoulder girdle stretches. They concluded that improvement to trunk muscle strength and compensatory strategies due to changes in flexibility in the lower extremities had made the head position backward and the postural alignment improve. It shows the possibility that posture is improved by a systemic change. Meanwhile, it is conceivable that it may be difficult to see changes in head posture or spinal column curve angle using the back extension or full-body exercises as in this study.

Our study suggests that the back extensor or full-body exercise may be useful in maintaining postural alignment, improving physical function and performance. The intended parent set of this study was a group of day service center-using community-dwelling older adults in an area in which many people work in agriculture. One characteristic is that there is a high level of physical functioning and cognitive function among the day service center users. It is essential to consider this context when generalizing the study findings to other older adults.

The pre- and post-intervention assessments in this study were conducted in faithful accordance with manuals with detailed descriptions of measurement procedures, and the measurement values in each measurement period were 
measured without confirming in advance to minimize information bias. However, because the subject sorting, intervention, assessment, and statistical analysis were all conducted by one study supervisor, the lack of blinding may have affected the results.

\section{Conclusion}

For the older adults in community-dwelling, we conducted an exercise focused on back extensor strengthening for 6 months. Subjects who adequately completed the exercises showed a decrease in the knee angle at "best" posture, improvements in physical function and performance, but there were no changes in self-efficacy and HQOL. Verifying the effect size in the post-hoc analysis, the body parts that showed changes to postural alignment differed between groups. Back extensor strengthening did not necessarily improve postural alignment, but its effects on postural alignment might have been different between groups.

Acknowledgements: We sincerely thank all the subjects who gave us their understanding and cooperation in this study as well as all of the staff at the Hiraka Day Service Center.

Conflict of Interest: There is no conflict of interest to disclose.

\section{References}

1) Kado DM, Browner WS, et al.: Vertebral fractures and mortality in older women: a prospective study. Study of Osteoporotic Fractures Research Group. Arch Intern Med. 1999; 159: 12151220.

2) Schneider DL, von Mühlen D, et al.: Kyphosis does not equal vertebral fractures: the Rancho Bernardo study. J Rheumatol. 2004; 31: 747-752.

3) Kado DM, Prenovost K, et al.: Narrative review: hyperkyphosis in older person. Ann Intern Med. 2007; 147: 330-338.

4) Hirose D, Ishida K, et al.: Posture of the trunk in the sagittal plane is associated with gait in community-dwelling elderly population. Clin Biomech. 2004; 19: 57-63.

5) Kado DM, Huang MH, et al:: Hyperkyphotic posture and poor physical functional ability in older community-dwelling men and women: the Rancho Bernardo study. J Gerontol A Biol Sci Med Sci. 2005; 60: 633-637.

6) Fukuda A, Harada K, et al.: Relationship of spinal curvature with physical functions and history of falls in elderly Japanese women. Phys Ther Japan. 2013; 40: 465-472.

7) Kado DM, Huang MH, et al.: Hyperkyphotic posture and risk of injurious falls in older persons: the Rancho Bernardo Study. J Gerontol A Biol Sci Med Sci. 2007; 62: 652-657.

8) Miyakoshi N, Itoi E, et al.: Impact of postural deformities and spinal mobility on quality of life in postmenopausal osteoporosis. Osteoporos Int. 2003; 14: 1007-1012.
9) Katzman WB, Wanek L, et al.: Age-related hyperkyphosis: its causes, consequences, and management. J Orthop Sports Phys Ther. 2010; 40: 352-360.

10) Itoi E and Sinaki M: Effect of back-strengthening exercise on posture in healthy women 49 to 65 years of age. Mayo Clin Proc. 1994; 69: 1054-1059.

11) Hongo M, Itoi E, et al.: Effect of low-intensity back exercise on quality of life and back extensor strength in patients with osteoporosis: a randomized controlled trial. Osteoporos Int. 2007; 18: 1389-1395.

12) Bansal S, Katzman WB, et al.: Exercise for improving agerelated hyperkyphotic posture: a systematic review. Arch Phys Med Rehabil. 2014; 95: 129-140.

13) Bergström I, Bergström K, et al.: Back extensor training increases muscle strength in postmenopausal women with osteoporosis, kyphosis and vertebral fractures. J Adv Physiother. 2011; 13: 110-117.

14) Ball JM, Cagle P, et al.: Spinal extension exercises prevent natural progression of kyphosis. Osteoporos Int. 2009; 20: 481-489.

15) Benedetti MG, Berti L, et al.: Effects of an adapted physical activity program in a group of elderly subjects with flexed posture: clinical and instrumental assessment. J Neuroeng Rehabil. 2008; 5: 32 .

16) Katzman WB, Sellmeyer DE, et al:: Changes in flexed posture, musculoskeletal impairments, and physical performance after group exercise in community-dwelling older women. Arch Phys Med Rehabil. 2007; 88: 192-199.

17) Gelb DJ and St Laurent RT: Alternative calculation of the global clinical dementia rating. Alzheimer Dis Assoc Disord. 1993; 7: 202-211.

18) Shrout PE and Fleiss JL: Intraclass correlations: uses in assessing rater reliability. Psychol Bull. 1979; 86: 420-428.

19) Landis JR and Koch GG: The measurement of observer agreement for categorical data. Biometrics. 1977; 33: 159-174.

20) Mannion AF, Knecht K, et al.: A new skin-surface device for measuring the curvature and global and segmental ranges of motion of the spine: reliability of measurements and comparison with data reviewed from the literature. Eur Spine J. 2004; 13: 122-136.

21) Houki N: Posture analysis of Japanese healthy adults and patients with low back pain and back pain using the Spinal Mouse $^{\circledR}$. J Kyorin Med Soc. 2010; 41: 1-11.

22) Endo T, Tsusima E, et al.: The reliability of trunk extensor strength measurements, utilizing hand held dynamometer, of geriatric patients presenting kyphosis. Annual Rep Tohoku Sect J Phys Ther Assoc. 2014; 26: 172-176.

23) Csuka M and McCarty DJ: Simple method for measurement of lower extremity muscle strength. Am J Med. 1985; 78: 77-81.

24) Morala D and Shiomi T: Assessing reliability and validity of physical performance test for the Japanese elderly. J Phys Ther Sci. 2004; 16: 15-20.

25) Reuben DB and Siu AL: An objective measure of physical function of elderly outpatients: The Physical Performance Test. J Am Geriatr Soc. 1990; 38: 1105-1112.

26) Tinetti ME, Richman D, et al.: Falls efficacy as a measure of 
fear of falling. J Gerontol. 1990; 45: P239-P243.

27) Fukuhara S and Suzukamo Y: Manual of the SF-8 Japanese version. Institute for Health Outcomes \& Process Evaluation research, 2004, pp. 5-118.
28) Mizumoto A and Takeuchi O: Basics and considerations for reporting effect sizes in research papers. Study in English language teaching. 2008; 31: 57-66. 